\title{
Heat Development in the Pulp Chamber During Curing Process of Resin-Based Composite Using Multi-Wave LED Light Curing Unit
}

This article was published in the following Dove Press journal: Clinical, Cosmetic and Investigational Dentistry

\author{
Bo Wold Nilsen ${ }^{1}, *$ \\ Mathieu Mouhat (iD ${ }^{1, *}$ \\ Torbjørn Haukland (D) \\ Ulf Thore Örtengren ${ }^{1,2}$ \\ James B Mercer ${ }^{3}$ \\ 'Department of Clinical Dentistry, UiT- the \\ Arctic University of Norway, Troms $\varnothing$, \\ Norway; ${ }^{2}$ Department of Cariology, \\ Institute of Odontology/Sahlgrenska \\ Academy, Gothenburg, Sweden; \\ ${ }^{3}$ Department of Medical Biology, UiT - the \\ Arctic University of Norway, Tromsø, \\ Norway \\ *These authors contributed equally to this \\ work
}

Objective: The study aimed to investigate factors contributing to heat development during light curing of a flowable bulk-fill resin-based composite $\left(\mathrm{SDR}^{\mathrm{TM}}\right.$, Lot \# 602000876 , Dentsply Sirona, Konstanz, Germany) (RBC).

Materials and Methods: Temperatures were measured with calibrated thermocouples. A multi-wave light-emitting diode (LED) light curing unit (LCU) was used (Ivoclar Vivadent, Schaan, Lichtenstein). In all experiments, the RBC was first cured (cured) for $30 \mathrm{~s}$ and, after $5 \mathrm{~min}$ of recovery time, received a second LCU irradiation (post-cured) for 30 $\mathrm{s}$. The exothermic reaction was measured by calculating the $\Delta$ temperature between cured and post-cured RBC. In a cylinder-shaped polymer mold, temperature was recorded inside of RBC during curing (part 1) and light transmission through RBC during curing was investigated (part 2). Pulpal temperatures were assessed in an extracted third molar during light curing (part 3). Data were statistically analyzed using one-way ANOVA $(\alpha=0.05)$.

Results: Increased thickness of RBC led to decreased pulp chamber temperatures. Inside $\mathrm{RBC}$, there was a large variation in heat development between the cured and post-cured groups ( $\mathrm{p}<0.05$ ). The cured group absorbed more LCU irradiation than the post-cured group. Conclusion: The irradiance of the LCU seemed to be a more important factor than exothermic reaction of RBCs for pulp chamber heat development. Flowable bulk-fill RBCs can act as a pulpal insulator against LCU irradiation, despite their exothermic curing reaction.

Keywords: dentistry, composite resins, LED dental curing light, pulp chamber, temperature

\section{Introduction}

In modern restorative dentistry, resin-based composites are used in more than 250 million direct restorations annually. ${ }^{1}$ The most common manner to initiate polymerization of these materials is by use of blue light with a wavelength between 380 and $500 \mathrm{~nm}$ and an irradiance $>450 \mathrm{~mW} / \mathrm{cm}^{2}$. When the initiator (eg, camphorquinone/tertiary amine (CQ/TA)) is subjected to sufficient light and irradiance, free radicals are created allowing the exothermic chain polymerization to occur. ${ }^{3}$ Today, most of the light curing units (LCUs) are based on the light-emitting diode (LED) technique, which has largely replaced quartz-tungsten-halogen (QHT) units. In contrast to QHT units, LEDs have the potential of converting electricity to light with near-unity efficiency, thus reducing heat generation. ${ }^{4}$ However, newer LED LCUs emit much higher irradiances than their first-generation counterparts. ${ }^{5}$ Thus, with increased irradiance, concerns have been raised about increased risk for pulp
Correspondence: Mathieu Mouhat Email mathieu.mouhat@uit.no 
and tissue damage. ${ }^{6-9}$ Zach and Cohen ${ }^{10}$ (1965) showed that $15 \%$ of intact monkey teeth developed pulp necrosis after exposure of the pulp to a temperature increase of $5.5^{\circ} \mathrm{C}$. Subsequently, LED LCUs with emission of more than one light spectrum were released on the market. These LED LCUs featured multi-wave spectrum, also known as polywave ${ }^{\circledR}$, multi-peak and broad banded, that produces both a longer blue wavelength $(425-500 \mathrm{~nm})$ and a shorter violet wavelength $(380-425 \mathrm{~nm})$. The blue "light" activates the most commonly used photoinitiator in RBC, camphorquinone, which has a maximum light absorbance close to $470 \mathrm{~nm}$. The violet "light" cures alternative photoinitiators such as phenyl-propanedione, Lucirin $^{\circledR}$ TPO and Ivocerin ${ }^{\circledR}$. In a previous study, it was shown that the risk of thermal injury to the pulp increased with decreasing dentin thickness and increased radiant exposure. ${ }^{11}$ Yet, other factors may also be important for heat development in the pulp.

In recent years, manufacturers have released a new range of resin-based composites, known as bulk-fill materials, which can be applied in thicker increments than conventional resin-based composites. Larger increments results in an increased volume of material and may lead to higher temperatures due to the exothermic reaction in the material during polymerization. ${ }^{12}$ Flowable bulk-fill materials contain less filler than universal resin-based composites (eg, less than 50 vol\% vs over 60 vol\%). They may, therefore, have an increased exothermic potential as compared to universal resin-based composites due to their higher monomer content. ${ }^{12}$ Yet, resin-based composites are known to be poor conductors of heat compared to other dental materials like amalgam. ${ }^{13,14}$ It can therefore be speculated whether resin-based composites can act as a heat insulator during light curing procedures, despite the exothermic curing reaction.

Furthermore, flowable bulk-fill resin-based composites are more translucent ${ }^{15}$ compared to conventional resinbased composites, thus more energy may pass through them during light curing. It is therefore plausible that the exothermic reaction, in addition to the absorbed light, determines the heat development in this range of resinbased composite materials. To our knowledge, these factors have not been yet investigated on this commercially available flowable bulk-fill resin-based composite (RBC).

The overall objective of this in vitro study was to investigate specific factors that contribute to heat development in the pulp chamber during light curing of a flowable bulk-fill resin-based composite. The specific objectives were: (1) to measure the temperature of the exothermic reaction in a flowable bulk-fill $\mathrm{RBC}, \mathrm{SDR}^{\mathrm{TM}}(\mathrm{RBC})$, and (2) to evaluate the effects which the exothermic reaction, the LED LCU irradiance and the insulating effects of the RBC have on pulp chamber temperatures during light curing. Our working hypothesis was that the exothermic reaction of the RBC increases pulp chamber temperature as well as LED LCU irradiance, the latter to a larger extent; and that RBC, with increased thickness, would have an insulating effect against pulp chamber overheating.

\section{Materials and Methods}

The LCU used was a mains powered polywave ${ }^{\circledR}$ Bluephase G2 ${ }^{\circledR}$ (serial \# P626170S591130) (Ivoclar Vivadent, Schaan, Lichtenstein). In the literature, this device has been reported to have a relatively uniform field of irradiance at the end of the light tip. ${ }^{16}$ All measurements were performed at high mode $\left(1200 \pm 100 \mathrm{~mW} / \mathrm{cm}^{2}\right.$ according to the manufacturer's specifications) for $30 \mathrm{~s}$. The LCU was fixed into an adjustable precision gantry (\#55025, Edmunds Optics, Barrington, NJ, USA) for reproducible placement with $0.1 \mathrm{~mm}$ accuracy.

The irradiance values of the LCU were regularly controlled by a calibrated laboratory-grade NIST-referenced USB4000 spectrometer (Managing Accurate Resin Curing (MARC) System, Bluelight Analytics Inc., Halifax, Canada). The measured irradiance was stable throughout all experiments $\left(1400 \pm 100 \mathrm{~mW} / \mathrm{cm}^{2}\right)$. The same spectrometer was used to investigate the irradiance through the $\mathrm{RBC}$ in Part 2.

Temperatures were recorded using $0.2 \mathrm{~mm}$ diameter, type $\mathrm{T}$ (copper constantan) thermocouples connected to an electronic recording device (N9002 Thermometer, Comark instruments Inc. Norwich, UK). All thermocouples were calibrated against a certified reference thermometer. The latter was in its turn, calibrated against a traceable reference source (Norwegian Standards Organization). The accuracy was $0.1^{\circ} \mathrm{C}$ and all thermocouples were routinely recalibrated.

All experiments were performed with a flowable bulk-fill RBC (universal shade SDR ${ }^{\mathrm{TM}}$, Lot\# 1602000876 Konstanz, Germany) and applied using an RBC applicator (Dentsply Sirona, Konstanz, Germany). The material used in this study had a high monomer ratio. It was chosen since it can be considered as a worst-case material for evaluation of the exothermic reaction contributing to heat development during polymerization. According to the manufacturer, the filler 
loading of $\mathrm{SDR}^{\mathrm{TM}}$ is $45 \%$ by volume. The main resin in $\mathrm{SDR}^{\mathrm{TM}}$ is a modified urethane dimethacrylate (UDMA) with a molecular weight of $849 \mathrm{~g} / \mathrm{mol}$ compared to $513 \mathrm{~g} / \mathrm{mol}$ for Bis-GMA and $471 \mathrm{~g} / \mathrm{mol}$ for common UDMA. ${ }^{17}$

Cycles were performed as follows: in all experiments, the RBC was first cured (cured) for $30 \mathrm{~s}$ and, after 5 min of recovery time, it received a second LCU irradiation (postcured) for $30 \mathrm{~s}$. Since the sample was fully cured, the temperature increase during the second LCU irradiation (post-cured) was caused only by the LCU and had no exothermic component involved. To determine the contribution of exothermic reaction, the $\Delta$ temperature between cured and post-cured was calculated. The recovery time chosen was based on performed pilot studies. One operator performed all the measurements.

\section{Part I Measurement of Exothermic Reaction \\ Setup}

A cylinder-shaped polymer mold (diameter: $4 \mathrm{~mm}$, height:

2, 4 and $6 \mathrm{~mm}$ ) from 3M/ESPE (Saint Paul, MN, USA) was used. The tip of a thin thermocouple was positioned $1.5 \mathrm{~mm}$ inside the cylinder and the LCU was positioned $1.0 \mathrm{~mm}$ over the center of the cylinder. All temperature data were exported to Excel 2016 (Microsoft Corporation, Redmond, WA, USA) for analyses (Figure 1).

\section{Procedure}

The cylinder with the thermocouple was filled with the $\mathrm{RBC}$ and one curing cycle performed. The experiment was repeated 5 times for each of the thicknesses evaluated (2, 4 and $6 \mathrm{~mm}$ ). Between each curing cycle, the thermocouple wire was cut and the cured RBC was removed from the cylinder. Following this, the tip of each thermocouple was repaired and re-calibrated prior to being re-installed in the cylinder for the next curing cycle.

\section{Part 2 Absorption of the LCU Irradiation in the RBC}

To evaluate the absorption of the LCU irradiation in the $\mathrm{RBC}$, the transmission of irradiance was measured through different depths of the cured and the post-cured RBC during light curing.

\section{Setup}

A transparent polyethylene sheet was placed on top of the spectrometer. The same cylinders ( 2 and $4 \mathrm{~mm}$ high) as in part 1 were used. Each cylinder was placed over the center

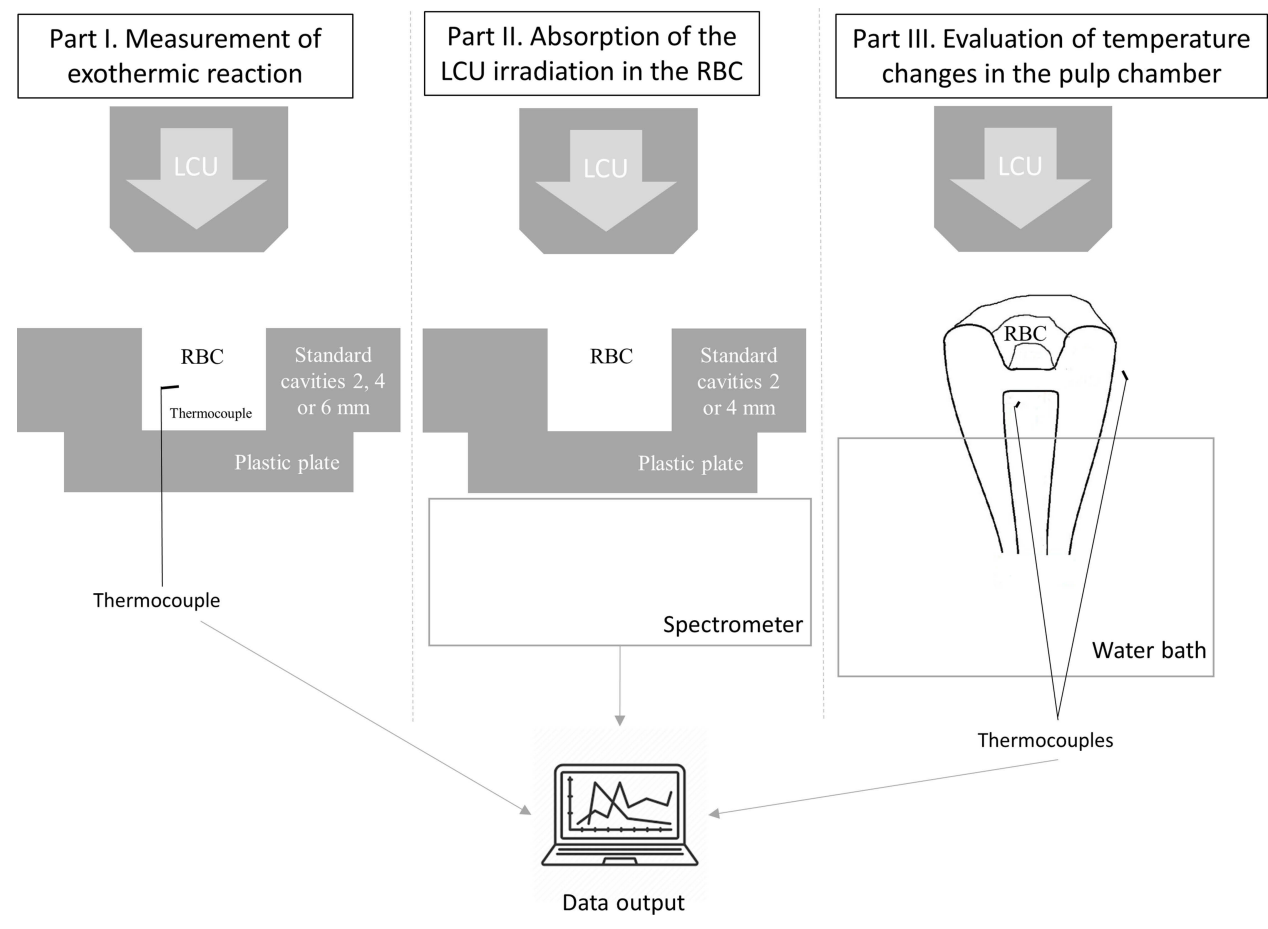

Figure I Experimental setup for the measurement of the heat generated by resin-based composites (RBC), exothermic reaction and LED light curing unit (LCU) (part I and III) and for the measurement of absorption of LED LCU irradiation in the resin-based composite (part II). 
of the spectrometer and the tip of the LCU was positioned centrally $1.0 \mathrm{~mm}$ above the cylinder (Figure 1).

\section{Procedure}

In the $2 \mathrm{~mm}$ high cylinder, three curing cycles were performed with 1 and $2 \mathrm{~mm}$ of RBC. One curing cycle was performed with the $4 \mathrm{~mm}$ cylinder completely filled with RBC. The irradiance was measured through both the cured and the post-cured RBC during the 30s curing cycles. For reference, the irradiance was checked in empty cylinders.

\section{Part 3 Evaluation of Temperature Changes in the Pulp Chamber}

An extracted, caries-free third molar was used for the evaluation of the temperature changes in the pulp chamber during light curing of the RBC. The tooth was stored in $0.5 \%$ chloramine $\mathrm{T}$ solution according to ISO/TS 11405:2015 in a refrigerator $\left(4 \pm 1^{\circ} \mathrm{C}\right)$ prior to use. The experiments were carried out within 3 months of extraction. A proximal cavity was prepared with a turbine (GENTLEsilince LUX 8000 B, KAVO, Germany) with a cylindrical diamond bur (012, Comet, Gebr. Brasseler $\mathrm{GmbH} \&$ Co. KG, Lemgo Germany). The cavity was prepared with diverging walls with continuation out to the mesial side. This created a preparation with three flat walls and a flat pulpal floor (Figure 2A and B). Adjustments were performed with a $1.2 \mathrm{~mm}$ diameter circular diamond bur (Komet, Gebr. Brasseler GmbH \& Co. KG. Lemgo, Germany). The cavity was polished with a yellow RBC polisher (Y2, Top Dent, DAB Dental, Upplands Väsby, Sweden).

The thickness of the dentin was initially determined with radiography (Planmeca Intra X-ray unit with Romexis, Planmeca Oy, Helsinki, Finland) before and after preparation, with the aim of leaving $1 \mathrm{~mm}$ of dentin between the cavity floor and the pulp chamber ceiling.

According to a recent protocol, ${ }^{11}$ the apex was cut and a channel was prepared through the root canal with K-files \#35 and \#70 (K-file Nitiflex, Dentsply Sirona, Ballaigues, Switzerland) to enable placement of the thermocouple in the pulp chamber (Figures $2 \mathrm{~A}$ and B). The position of the thermocouple was verified with radiography to ensure that the tip of the thermocouple was located close to the prepared cavity. After completion of the experiment, the position of the thermocouple and dentin thickness was checked using a micro computed tomograph (Micro-CT) (Bruker Skyscan1272, Bruker, Kontich, Belgium). The Micro-CT scanning was performed at $19.79 \mu \mathrm{m} \cdot$ voxel and the projections were reconstructed with filtered backprojection, using the software nRecon (Bruker, Kontich, Belgium). Distance measurements were carried out in Dataviewer software (Bruker, Kontich, Belgium). To improve thermal conductance in the pulp chamber, it was filled with glycerol. A glass ionomer cement (Fuji I ${ }^{\circledR}, \mathrm{GC}$ Corp. Tokyo, Japan) was used to seal the apex, which also served to hold the thermocouple in place. To ensure thickness control when applying the RBC, the buccal wall of

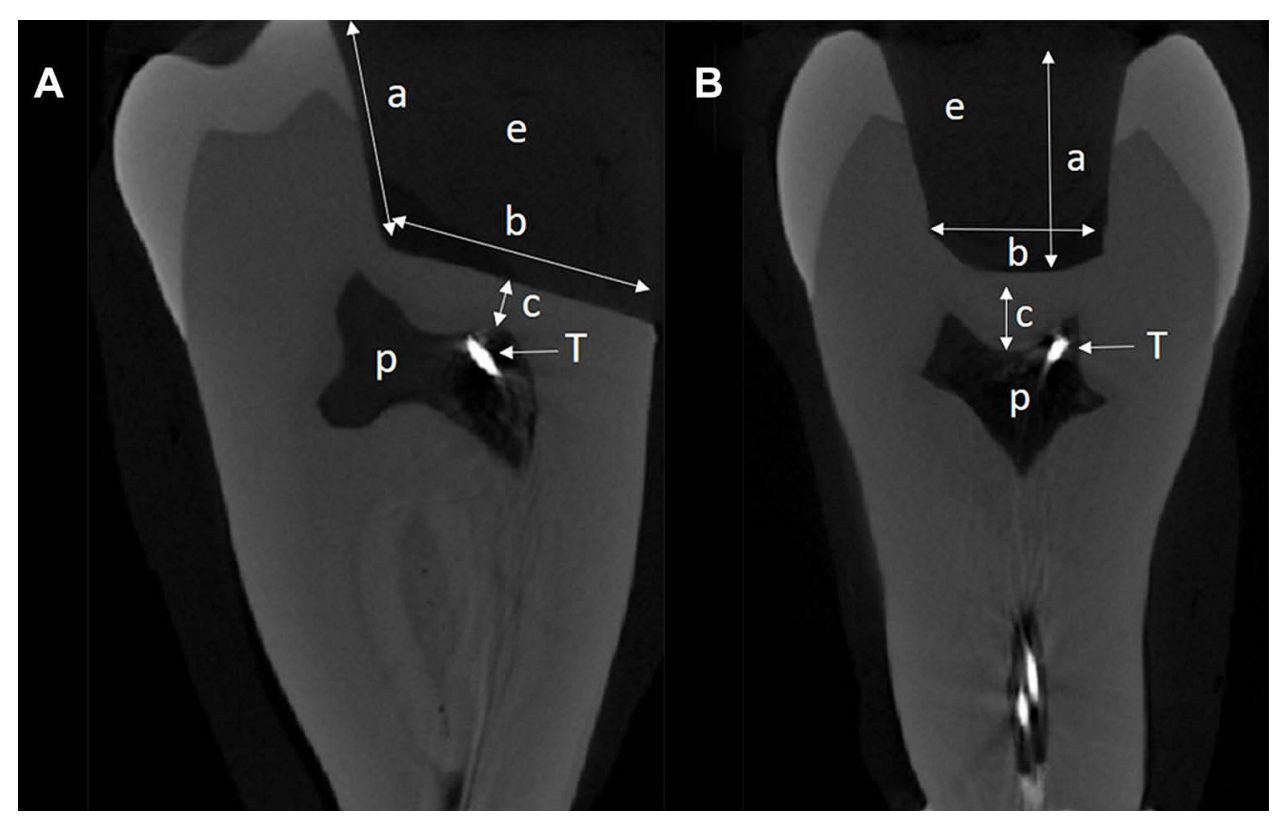

Figure 2 Micro-CT. Cross-section of the tooth. (A) Mesial-distal view: p-pulp chamber, T-tip of the thermocouple, e-empty cavity, a=4 mm, b=8 mm. (B) Bucco-lingual view: P-pulp chamber, T-tip of the thermocouple, e-empty cavity, a= $4 \mathrm{~mm}, \mathrm{c}=\mathrm{I} \mathrm{mm}$. 
the cavity was marked with a permanent marker at a distance of 1, 2, 3 and $4 \mathrm{~mm}$ from the floor of the cavity. A plastic matrix-band (Hawe Neos Dental, Bioggio, Switzerland) attached to a holder (Nyström, Sweden) was used to seal the cavity on the mesial side. This design enabled the removal of the RBC with a sharp carver (Carver N 3, Parainen, Finland) after each curing cycle. To allow the repeated use of the same tooth, adhesive material was not used. Adhesives have been shown to not significantly influence the pulp chamber temperatures during light curing of RBC. ${ }^{18}$

\section{Control of Baseline Temperatures}

In an attempt to mimic the humidity and temperature in the oral cavity, a setup similar to that described by Mouhat et al, ${ }^{11}$ (2017) was used. Briefly, this consisted of mounting the tooth so that its roots were immersed under water in a thermostatically controlled circulating water bath (AH15L HT, VWR International, Radnor, PA, USA) maintained at $36.2 \pm 0.2^{\circ} \mathrm{C}$. A polystyrene plate was taped to the edge of the water bath to ensure minimum movement of the tooth. Two additional thermocouples were placed: one for measuring the water temperature and one to monitor the air temperature close to the coronal part of the tooth, which was at $23 \pm 2{ }^{\circ} \mathrm{C}$ throughout the experiments (Figure 1).

\section{Procedure}

The cavity was filled with $\mathrm{RBC}$ up to the respective marking on the buccal wall. The RBC flowed freely and no instrument was used for manipulation. The LCU was placed over the cavity in close contact with the cusps of the tooth and the curing cycle performed. Three curing cycles were conducted for each of the thicknesses (1, 2, 3 and $4 \mathrm{~mm}$ ). To control the accuracy of the volume of the applied material for the respective depths, the $\mathrm{RBC}$ was removed from the cavity after the curing cycle and weighed to an accuracy of $0.1 \mathrm{mg}$ (Sartorius AG, Goettingen, Germany).

The thermocouple temperatures were recorded every second with a temperature logger (OQ610 temperature logger, Grant instruments. Cambridge, England) and using the software SquirrelView 3.9 (Grant instruments. Cambridge, England). All temperature data were exported to Excel 2016 (Microsoft Corporation, Redmond, WA, USA) for analyses.

\section{Data Collection and Statistics}

Graphing and statistical analysis were conducted using Sigmaplot 13 (Systat. Software, San Jose, CA, USA). In parts 1 and 3, comparison of means between groups was performed with one-way analysis of Variance with an alpha value of 0.05 . Normality (Shapiro-Wilk) and equal variance tests (Brown-Forsythe) were performed prior to the ANOVA. In part 3, correlation and regression analyses were conducted using the weight of RBC sample as a proxy for thickness of the sample.

\section{Ethics}

Ethical permission was asked for from the Norwegian Regional Committee for Medical and Health Research Ethics (REK). The committee concluded that such permission was not required (2015/234/REK Nord).

\section{Results}

\section{Part I Measurement of the Exothermic Reaction}

Temperatures and temperature differences between cured and post-cured RBC after 30s of light curing in the standard cylinders are shown in Table 1. The temperature difference between the cured and the post-cured RBCs after $30 \mathrm{~s}$ of light curing in the 2,4 and $6 \mathrm{~mm}$ group was $10.1{ }^{\circ} \mathrm{C}, 12.9^{\circ} \mathrm{C}$ and $13.3^{\circ} \mathrm{C}$, respectively. The differences were statistically significant $(p<0.05)$. In Figure 3 , the temperature development inside the $\mathrm{RBC}$ during light curing is shown. The temperatures reached were $60.8^{\circ} \mathrm{C}$, (30 s), $59.9^{\circ} \mathrm{C}(35 \mathrm{~s})$, and $45.6^{\circ} \mathrm{C}(40$ and $45 \mathrm{~s})$, for the cured groups and $50.7^{\circ} \mathrm{C},(30 \mathrm{~s}), 42.3^{\circ} \mathrm{C}(40 \mathrm{~s})$, and $34.9^{\circ} \mathrm{C}$ $(55 \mathrm{~s})$, for the post-cured groups at 2,4 and $6 \mathrm{~mm}$, respectively. The cured RBC showed a rapid increase in temperature during the first $6-7 \mathrm{~s}$, while the post-cured material showed a linear temperature increase until the end of light curing (Figure 3).

Table I Mean Temperatures Inside the Resin-Based Composite (Celsius Scale) (Mean \pm SD). After $30 \mathrm{~s}$ of Light Curing and Differences Between Cured and Post-Cured Groups are Shown (Temp. $\Delta$ ). Different Letter (a-f) Indicates Statistical Significance Between Groups $(P<0.05) . n=5$ per Group

\begin{tabular}{|l|l|l|l|}
\hline \multirow{2}{*}{$\begin{array}{l}\text { Group Based on } \\
\text { Composite } \\
\text { Thicknesses }\end{array}$} & \multicolumn{3}{|l|}{ Temperature Inside the Composite } \\
\cline { 2 - 4 } & Cured & Post-Cured & Temp. $\Delta$ \\
\hline $2 \mathrm{~mm}$ & $60.8 \pm 1.60^{\mathrm{a}}$ & $50.7 \pm 1.00^{\mathrm{b}}$ & $10.1 \pm 1.13$ \\
$4 \mathrm{~mm}$ & $53.6 \pm 2.94^{\mathrm{c}}$ & $40.7 \pm 2.37^{\mathrm{d}}$ & $12.9 \pm 0.84$ \\
$6 \mathrm{~mm}$ & $45.1 \pm 1.14^{\mathrm{e}}$ & $31.8 \pm 0.76^{\mathrm{f}}$ & $13.3 \pm 0.62$ \\
\hline
\end{tabular}




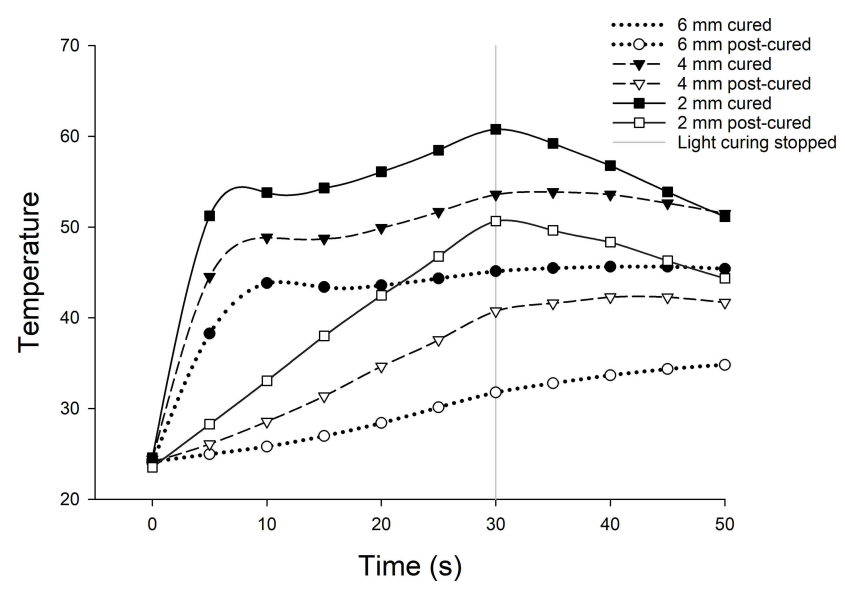

Figure 3 Mean temperature $(n=5)$ inside of SDR ${ }^{T M}$ during curing of each group. At 30 seconds, all measurements between the groups were significantly different $(p<0.05)$.

\section{Part 2 Transmission of Irradiance Through the RBC}

Similar trends of absorption of LCU irradiation were observed in all groups of cured and post-cured RBCs, respectively, independent of the depth of RBC. Representative results of transmission of irradiance are presented (Figure 4). As shown in the figure, the cured RBC absorbed more energy (ie, had a lower transmission of irradiance) during the first 6-7 s, before the transmission of irradiance stabilized. In contrast to this, the transmitted irradiance through the post-cured groups (only shown for the $2 \mathrm{~mm}$ group) reached a higher level of transmission of light in less than 0.25 s. In Figure 4, it can also be seen that transmission of light through the

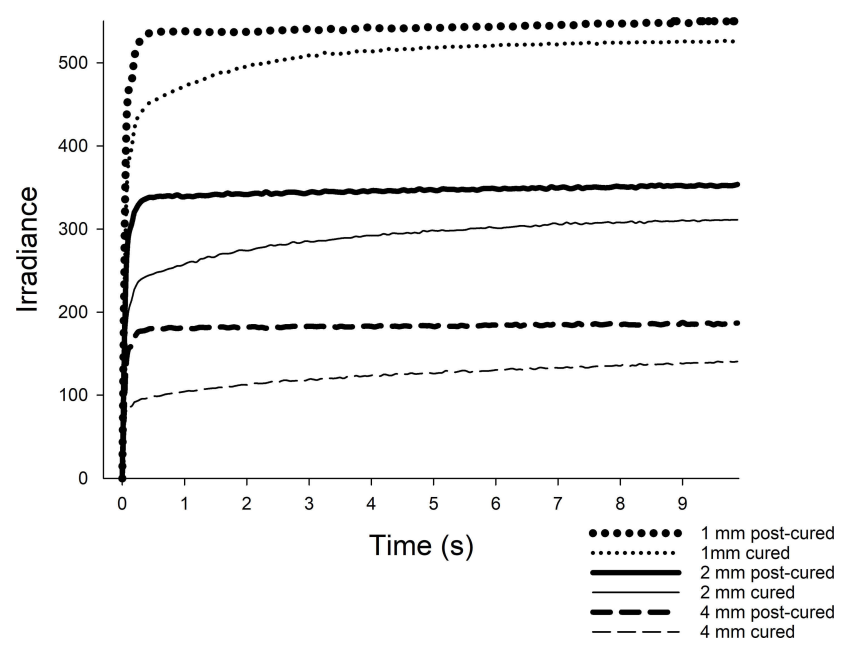

Figure 4 The irradiance measured through three samples of $1 \mathrm{~mm}, 2 \mathrm{~mm}$ and $3 \mathrm{~mm}$ of cured (lines) and post-cured resin-based composite (respectively, dots solid lines and dashes). The same line-contour indicates the same sample.
RBC decreases with an increasing amount of material. For example, in the $4 \mathrm{~mm}$ cured group the irradiance through the material was less than $120 \mathrm{~mW} / \mathrm{cm}^{2}$

\section{Part 3 Evaluation of Temperature Changes in the Pulp Chamber}

Table 2 presents the mean maximum temperatures after 30 $\mathrm{s}$ of light curing for each group. When LED LCU irradiation was performed in the empty cavity, the pulp chamber temperature increased by $7.2^{\circ} \mathrm{C}$ up to $42.6^{\circ} \mathrm{C}$. The pulp chamber temperature increased by $6.8^{\circ} \mathrm{C}$ up to $42.2^{\circ} \mathrm{C}$, $6.2^{\circ} \mathrm{C}$ up to $41.6^{\circ} \mathrm{C}$ and $6.1^{\circ} \mathrm{C}$ up to $41.5^{\circ} \mathrm{C}$ with $1 \mathrm{~mm}$ thickness of RBC cured, $1 \mathrm{~mm}$ RBC post-cured and $2 \mathrm{~mm}$ RBC cured, respectively.

The effect of thickness between each group was examined and a significant difference was found between the empty cavity group and the cured groups at 3 and $4 \mathrm{~mm}(\mathrm{p}<0.05)$. This phenomenon was also seen in all the post-cured groups, regardless of thickness. In addition, except for the $1 \mathrm{~mm}$ group, a statistically significant difference between cured and post-cured for all thicknesses was evident $(p<0.05)$. The variance in weight of the removed RBC from the tooth cavity suggested that height was not a suitable parameter for the correlation analysis. Thus, the weight of each sample of removed $\mathrm{RBC}$ was used instead of height for the correlation analysis. Figure 5 shows that the pulp chamber temperature decreased with increasing weight/thickness of material and that cured $\mathrm{RBC}$ had higher pulp chamber temperature than post-cured $\mathrm{RBC}$ at the same thickness of $\mathrm{RBC}$ $(p<0.0001)$. The micro-CT examination of the tooth showed that the distance from the cavity floor to the thermocouple and to the ceiling of the pulp was $1.31 \mathrm{~mm}$ and $0.87 \mathrm{~mm}$, respectively.

Table 2 Mean Temperatures in the Pulp Chamber (Celsius Scale) (Mean \pm SD). After $30 \mathrm{~s}$ of Light Curing and Differences Between Cured and Post-Cured Groups are Shown (Temp. $\Delta$ ). Different Letter (a-i) Indicates Statistical Significance Between Groups $(P<0.05)$. $n=3$ per Group

\begin{tabular}{|l|l|l|l|}
\hline \multirow{2}{*}{$\begin{array}{l}\text { Group Based on } \\
\text { Composite } \\
\text { Thicknesses }\end{array}$} & \multicolumn{3}{|l|}{ Pulp Chamber Temperature } \\
\cline { 2 - 4 } & Cured & Post-Cured & Temp. $\Delta$ \\
\hline $0 \mathrm{~mm}$ (empty cavity) & $42.6 \pm 0.15^{\mathrm{a}, \mathrm{b}, \mathrm{c}}$ & $42.6 \pm 0.15^{\mathrm{a}, \mathrm{b}, \mathrm{c}}$ & 0 \\
$\mathrm{I} \mathrm{mm}$ & $42.2 \pm 0.23^{\mathrm{b}, \mathrm{c}, \mathrm{d}}$ & $41.6 \pm 0.20^{\mathrm{d}}$ & $0.6 \pm 0.09$ \\
$2 \mathrm{~mm}$ & $41.5 \pm 0.51^{\mathrm{c}, \mathrm{d}}$ & $40.2 \pm 0.46^{\mathrm{e}}$ & $1.3 \pm 0.28$ \\
$3 \mathrm{~mm}$ & $39.6 \pm 0.06^{\mathrm{e}, \mathrm{f}}$ & $38.4 \pm 0.25^{\mathrm{g}}$ & $1.2 \pm 0.16$ \\
$4 \mathrm{~mm}$ & $39.6 \pm 0.36^{\mathrm{e}, \mathrm{h}}$ & $37.6 \pm 0.36^{\mathrm{i}}$ & $2.0 \pm 0.14$ \\
\hline
\end{tabular}




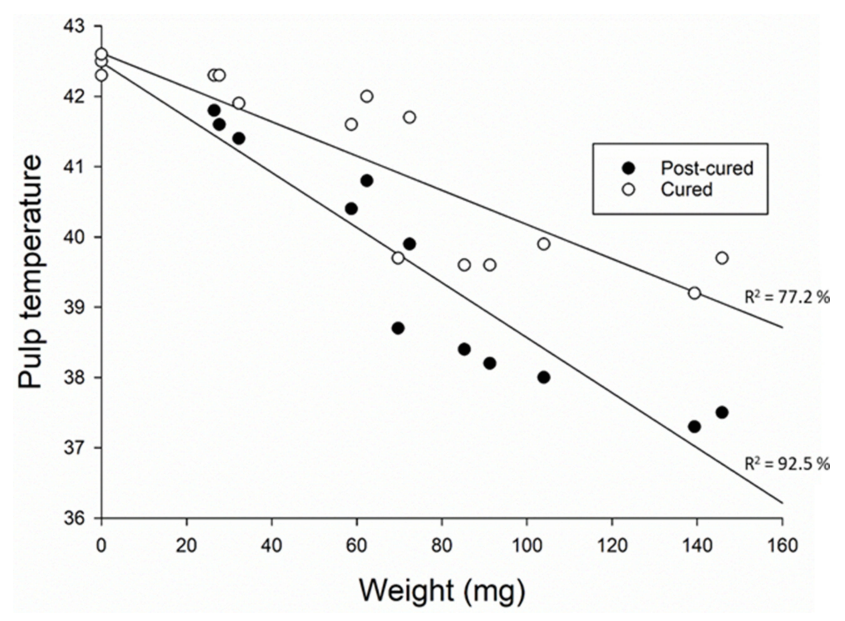

Figure 5 The pulp chamber temperature (Y-axis) plotted against weight/thickness of the resin-based composite $(X$-axis). The three points at $0 \mathrm{mg}$ represent curing cycles performed in the empty cavity. Cured RBC: linear regression coefficient $\beta=-0.02$; $p<0.000$ I. Post-cured RBC: linear regression coefficient $\beta=-0.04 ; p<0.0001$.

\section{Discussion}

In this laboratory study, we have investigated factors that contribute to heat development in the pulp chamber during light curing of the flowable bulk-fill material, $\mathrm{SDR}^{\mathrm{TM}}$ (RBC). To the best of the authors' knowledge, these factors have not been investigated in this flowable bulk-fill $\mathrm{RBC}$. Heat development is a complex process encompassing irradiance of LCU, distance to the pulp chamber, absorption of light-energy and the exothermic- and the insulating properties of the $\mathrm{RBC}$ material. By keeping the anatomical features the same across measurements, we have been able to assess both the exothermic and insulating properties of varying amounts of RBC. The results of the present study confirmed our hypothesis demonstrating that both the exothermic reaction of the $\mathrm{RBC}$ and the irradiance of the LCU contributed to pulp chamber heat development; the latter increased pulp chamber temperature to a larger extent. RBC acted as a pulp insulator against LCU irradiation when used in layers exceeding $2 \mathrm{~mm}$ which also confirmed our hypothesis.

The temperature findings in part 1 showed a large difference in temperatures measured inside the cured and post-cured RBC (Figure 3). The $\Delta$ temperature between cured and post-cured RBC was calculated to determine the exothermic reaction. While the temperature observed in part 1 is not directly extrapolatable to the clinical situation as the conductive properties of the cylinder-shaped polymer mold and dental hard tissue are not similar, ${ }^{19}$ it shows that the relative increase in temperature between cured and post-cured is significant when considered in isolation. In part 3 the pulp chamber temperature was measured. We found higher pulp chamber temperature for the cured RBC compared to the post-cured RBC (Figure 5). We assumed that for the cured $\mathrm{RBC}$ the temperature increase is a cumulative result of exothermic reaction and LCU irradiation while for the post-cured the temperature increase was only a result of LCU irradiation. The differences in the temperature increase between cured and post-cured $\mathrm{RBC}$, which was $0.6^{\circ} \mathrm{C}$ for the $\mathrm{RBC}$ with smaller weight (20 mg) and $2^{\circ} \mathrm{C}$ for the $\mathrm{RBC}$ with greater weight (140 mg), are assumed to be as a result of an exothermic reaction. The pulp chamber temperature increase as a result of the LCU irradiation (post-cured RBC) was higher than the temperature increase due to the exothermic reaction (the difference between cured and post-cured $\mathrm{RBC}$ ). Therefore, irradiation of the LCU seemed to be a more important factor compared to the exothermic reaction of the RBC for heat development in the pulp chamber. Interestingly, during light curing, we found that increased weights of RBC had an insulating effect on pulp chamber temperatures, regardless of the cured or post-cured situation. These models explained $92.5 \%$ of the variations in the pulp chamber temperature for post-cured and 77.2\% for cured showing a good fit of the models (Figure 5). Polymers, such as RBCs are known to be poor conductors of heat, and this can partly explain this insulating effect. ${ }^{13}$ The dentin thickness is also of importance; a study comparing $0.5 \mathrm{~mm}$ vs $1 \mathrm{~mm}$ remaining dentin thicknesses showed that in the case of less thick remaining dentin pulp, chamber temperature increased more during bulkfill RBC curing with LED LCU compared to thicker remaining dentin. ${ }^{20}$ In the present study, the remaining dentin thickness was $1 \mathrm{~mm}$ and higher pulp chamber temperature increase might have been achieved with less remaining dentin thickness. Nevertheless, the maximum temperature increase in this study for the $1 \mathrm{~mm}$ group of cured and post-cured RBC as well as the $2 \mathrm{~mm}$ group of cured RBC exceeded the threshold of $5.5^{\circ} \mathrm{C}$ observed by Zach and Cohen ${ }^{10}$ (1965). A pulp chamber temperature increase of $6.8^{\circ} \mathrm{C}$ for the $1 \mathrm{~mm}$ group of cured $\mathrm{RBC}$ was observed. Even with $2 \mathrm{~mm}$ thickness of RBC, that might be considered more clinically relevant, a pulp chamber temperature increase of $6.1^{\circ} \mathrm{C}$ was observed. This might lead to deleterious effects on the pulp chamber.

With regard to absorption of the LCU irradiation, it was shown that the transmission through the $\mathrm{RBC}$ decreases when the depth of RBC is increased, which is in line with other recent studies. ${ }^{21,22}$ From a clinical point 
of view, this implies that with increasing amounts of RBC, less light-energy will reach the pulp chamber and contribute to heat development due to light absorption in the material. However, in the present model, this cannot accurately be assessed since the fluid of the pulp chamber was translucent. A translucent pulp chamber liquid has also been used in other models. ${ }^{23,24}$ In the model used in the present study, the pulp lacked ordinary blood circulation. However, we consider our results to be clinically relevant since pulp circulation has been shown to be limited when local anesthetics with vasoconstrictors are used during restorative procedures. ${ }^{25,26}$ Furthermore, a recent study comparing in vitro and in vivo models to investigate temperature increase when exposed to LED LCU concluded that at clinically relevant curing times only a small difference in temperature was observed. ${ }^{27}$

Another methodological consideration in this study was the accurate placement of the thermocouple in the pulp chamber. In part 3, we aimed to position the thermocouple close to the pulpal ceiling and the cavity floor. While using conventional radiography to assess the position of the thermocouple, the micro CT scan performed after the experiment showed that the thermocouple was, in fact, approximately $0.44 \mathrm{~mm}$ from the pulp ceiling (Figure 2). The recorded pulp temperature may have been higher if the thermocouple had been closer to the ceiling. The same might also be true if the thermocouple had been placed in the pulp horn closest to the cavity (Figure 2). Further experiments comparing the temperature effect of the placement of the thermocouple are needed in order to determine whether small changes in thermocouple placement have a large effect on the measured pulp temperature.

The highest mean temperature inside the RBC material $\left(60.8^{\circ} \mathrm{C}\right)$ was obtained with less volume of material, in the cured group (Table 1). This may be explained by the fact that the thermocouple was closer to the irradiated surface in the $2 \mathrm{~mm}$ group. The poor conduction of heat reported in polymers may have caused a heterogeneous distribution of heat in the material, suggesting that the volume closest to the surface may be warmer than the volume surrounding the thermocouple itself. In any case, the difference in temperature between the cured and post-cured group increased with increasing volume of material. This phenomenon is supported by the fact that increasing volumes of monomers have been shown to lead to higher temperatures during polymerization, ${ }^{12}$ which may be related to the conversion of reactive $\mathrm{C}=\mathrm{C}$ double bonds into $\mathrm{C}-\mathrm{C}$ bonds. ${ }^{28}$ In addition, the absorption of light-energy in cured materials was shown to be increased compared to the post-cured material (Part 2). This might also explain the temperature differences observed between cured and post-cured RBC. Thus, the temperature differences between the cured and the post-cured material may not entirely be due to the exothermic reaction and further investigations are needed to determine the role of light energy absorption to heat development within the RBC and in the pulp chamber. The manufacturer's recommendation for radiant exposure (ie, $20 \mathrm{~s}$ at $\geq 550 \mathrm{~mW} / \mathrm{cm}^{2}$ ) to achieve sufficient polymerization of the RBC was fulfilled in this study. Several recent studies investigating the same $\mathrm{RBC}$ as in the present study reported acceptable depth of cure and degree of conversion at $4 \mathrm{~mm},{ }^{29-31}$ confirming the manufacturer's recommendations. It is therefore reasonable to assume that no exothermic component was involved in the temperature change during the second light exposure (post-cured).

We found no significant difference in pulp chamber temperature between an empty cavity and the 1 and $2 \mathrm{~mm}$ groups of cured RBC. A plausible explanation is that the insulating effect of thin layers of RBC compensated for the heat generated in the exothermic reaction and the increased absorption of the LCU irradiation in the cured group. The post-cured RBC had a greater insulating effect in comparison to the cured RBC. This finding was in accordance with results obtained by Andreatta et $\mathrm{al}^{32}$ (2016).

This study investigated the flowable bulk-fill material $\mathrm{SDR}^{\mathrm{TM}}$ which is a representative material of the range of resin-based composites that share common following mechanisms: (i) photoinitiators with a higher photocuring activity for an increased polymerization and depth of cure; (ii) high molecular weight monomers to reduce shrinkage stress; (iii) improved flowability and (iv) increased translucency compared to conventional RBC. ${ }^{31}$ Nonetheless, $\mathrm{SDR}^{\mathrm{TM}}$ has a high monomer content compared to other commercially available flowable bulk-fill material and one must be cautious about extending our findings to all flowable bulk-fill resin-based composites. A recent study comparing a conventional bulk-fill paste RBC (Aura bulk fill, SDI, Bayswater, Perth, Australia) with 35 vol\% monomer content and the flowable bulk-fill material $\mathrm{SDR}^{\mathrm{TM}}$ with $55 \mathrm{vol} \%$ monomer content showed no difference in pulp chamber temperature rise even though the authors reported a higher exothermic reaction temperature of approximately $3^{\circ} \mathrm{C}$ for $\mathrm{SDR}^{\mathrm{TM}}$ compared to the conventional bulk-fill paste $\mathrm{RBC}^{33}$ 
Although several factors such as the type of $\mathrm{RBC},{ }^{34}$ the remaining thickness of dentin, ${ }^{23}$ the type of LED LCU ${ }^{35,36}$ and its distance to the tooth ${ }^{24}$ have been shown to be of particular importance for the pulp chamber temperature increase, our studies were carried out in a molar with a relatively large mass and caution should be implied with respect to heat development in the pulp chamber for other groups of teeth with less mass. ${ }^{37} \mathrm{~A}$ molar would, therefore, have a higher heat buffering capacity than an incisor or a premolar due to its large mass. Further studies are warranted to investigate pulp chamber temperature increase and buffering capacity with different groups and masses of teeth.

\section{Conclusion}

In conclusion, the results of this study support the notion that the irradiance of the LCU seems to be a more important factor than exothermic reaction of RBCs for pulp chamber heat development and that flowable bulk-fill RBCs can act as a pulpal insulator against LCU irradiation, despite their exothermic curing reaction.

Clinicians should consider the importance of different factors that can cause pulp tissue overheating. LED LCU might generate high temperature that could lead to deleterious effects on the pulp tissue, especially when small increments of $\mathrm{RBC}$ are used for restoration.

\section{Ethics Approval}

Ethical permission was requested from the Norwegian Regional Committee for Medical and Health Research Ethics (REK). The committee concluded that such permission was not required (2015/234/REK Nord).

\section{Acknowledgments}

We are grateful for Dr. Clyde Roggenkamp (Loma Linda University School of Dentistry, Loma Linda, CA, USA) for careful reading of the manuscript and for his insightful suggestions.

The publication charges for this article have been funded by a grant from the publication fund of UiT The Arctic University of Norway.

\section{Funding}

The study was financially supported by the Norwegian Directorate of Health (14/1493).

\section{Disclosure}

The authors report no conflicts of interest in this work.

\section{References}

1. Heintze SD, Rousson V. Clinical effectiveness of direct class II restorations - a meta-analysis. J Adhes Dent. 2012;14(5):407-431. doi:10.3290/j.jad.a28390

2. Price RB, Ferracane JL, Shortall AC. Light-curing units: a review of what we need to know. J Dent Res. 2015;94(9):1179-1186. doi:10. 1177/0022034515594786

3. Stansbury JW. Curing dental resins and composites by photopolymerization. J Esthet Dent. 2000;12(6):300-308. doi:10.1111/ j.1708-8240.2000.tb00239.x

4. Yam F, Hassan Z. Innovative advances in LED technology. Microelectronics J. 2005;36(2):129-137. doi:10.1016/j.mejo.200 4.11.008

5. Nomoto R, McCabe JF, Nitta K, Hirano S. Relative efficiency of radiation sources for photopolymerization. Odontology. 2009;97 (2):109-114. doi:10.1007/s10266-009-0105-8

6. Bouillaguet S, Caillot G, Forchelet J, Cattani-Lorente M, Wataha JC, Krejci I. Thermal risks from LED- and high-intensity QTH-curing units during polymerization of dental resins. J Biomed Mater Res B Appl Biomater. 2005;72(2):260-267. doi:10.1002/ jbm.b.30143

7. Aksakalli S, Demir A, Selek M, Tasdemir S. Temperature increase during orthodontic bonding with different curing units using an infrared camera. Acta Odontol Scand. 2014;72(1):36-41. doi:10. 3109/00016357.2013.794954

8. Eldeniz AU, Usumez A, Usumez S, Ozturk N. Pulpal temperature rise during light-activated bleaching. J Biomed Mater Res B Appl Biomater. 2005;72(2):254-259. doi:10.1002/jbm.b.30144|

9. Durey K, Santini A, Miletic V. Pulp chamber temperature rise during curing of resin-based composites with different light-curing units. Prim Dent Care. 2008;15(1):33-38. doi:10.1308/135576108783 328409

10. Zach L, Cohen G. Pulp response to externally applied heat. Oral Surg Oral Med Oral Pathol. 1965;19:515-530. doi:10.1016/00304220(65)90015-0

11. Mouhat M, Mercer J, Stangvaltaite L, Örtengren U. Light-curing units used in dentistry: factors associated with heat development-potential risk for patients. Clin Oral Investig. 2017;21(5):1687-1696. doi:10.1007/ s00784-016-1962-5

12. Ha J-Y, Kim S-H, Kim K-H, Kwon T-Y. Influence of the volumes of bis-acryl and poly (methyl methacrylate) resins on their exothermic behavior during polymerization. Dent Mater J. 2011;30(3):336-342. doi:10.4012/dmj.2010-188

13. Gedde U. Polymer Physics. London: Chapman \& Hall; 1995.

14. Anusavice KJ, Shen C, Rawls HR. Phillips' science of dental materials. Elsevier Health Sci. 2012.

15. Bucuta S, Ilie N. Light transmittance and micro-mechanical properties of bulk fill vs. conventional resin based composites. Clin Oral Investig. 2014;18(8):1991-2000. doi:10.1007/s00784-0131177-y

16. Shimokawa CA, Turbino ML, Harlow JE, Price HL, Price RB. Light output from six battery operated dental curing lights. Mater Sci Eng C Mater Biol Appl. 2016;69:1036-1042. doi:10.1016/j.msec.2016.07.033 17. Dentsply Sirona. Scientific Manual SDR; 2017.

18. Hannig M, Bott B. In-vitro pulp chamber temperature rise during composite resin polymerization with various light-curing sources. Dent Mater. 1999;15(4):275-281. doi:10.1016/S0109-5641(99)00047-0

19. Balestrino A, Verissimo C, Tantbirojn D, Garcia-Godoy F, Soares CJ, Versluis A. Heat generated during light-curing of restorative composites: effect of curing light, exotherm, and experiment substrate. $A m$ J Dent. 2016;29(4):234-2240.

20. Akarsu S, Aktug Karademir S. Influence of bulk-fill composites, polymerization modes, and remaining dentin thickness on intrapulpal temperature rise. Biomed Res Int. 2019;4250284. doi:10.1155/2019/4250284 
21. Maghaireh GA, Price RB, Abdo N, Taha NA, Alzraikat H. Effect of thickness on light transmission and vickers hardness of five bulk-fill resin-based composites using polywave and single-peak light-emitting diode curing lights. Oper Dent. 2019;44(1):96-107. doi:10.2341/17-163-L

22. Santini A, Naaman R, Aldossary M. Light energy transmission and Vickers hardness ratio of bulk-fill resin based composites at different thicknesses cured by a dual-wave or a single-wave light curing unit. Am J Dent. 2017;30(2):65-70.

23. Choi SH, Roulet JF, Heintze SD, Park SH. Influence of cavity preparation, light-curing units, and composite filling on intrapulpal temperature increase in an in vitro tooth model. Oper Dent. 2014;39(5): E195205. doi:10.2341/13-068-L

24. Savas S, Botsali MS, Kucukyilmaz E, Sari T. Evaluation of temperature changes in the pulp chamber during polymerization of light-cured pulp-capping materials by using a VALO LED light curing unit at different curing distances. Dent Mater J. 2014;33 (6):764-769. doi:10.4012/dmj.2013-274

25. Yoon M, Lee S, Kim E, Park S. Doppler ultrasound to detect pulpal blood flow changes during local anaesthesia. Int Endod J. 2012;45 (1):83-87. doi:10.1111/j.1365-2591.2011.01960.x

26. Ahn J, Pogrel MA. The effects of $2 \%$ lidocaine with 1:100,000 epinephrine on pulpal and gingival blood flow. Oral Surg Oral Med Oral Pathol Oral Radiol Endod. 1998;85(2):197-202. doi:10.1016/ S1079-2104(98)90426-7

27. Runnacles P, Arrais CAG, Maucoski C, Coelho U, De Goes MF, Rueggeberg FA. Comparison of in vivo and in vitro models to evaluate pulp temperature rise during exposure to a Polywave ${ }^{\circledR}$ LED light curing unit. J Applied Oral Sci. 2019;27:e20180480. doi:10.1590/1678-7757-2018-0480

28. Kim S-H, Watts DC. Exotherm behavior of the polymer-based provisional crown and fixed partial denture materials. Dent Mater. 2004;20 (4):383-387. doi:10.1016/j.dental.2003.11.001
29. Goracci C, Cadenaro M, Fontanive L, et al. Polymerization efficiency and flexural strength of low-stress restorative composites. Dent Mater. 2014;30(6):688-694. doi:10.1016/j.dental.2014.03.006

30. Zorzin J, Maier E, Harre S, et al. Bulk-fill resin composites: polymerization properties and extended light curing. Dent Mater. 2015;31 (3):293-301. doi:10.1016/j.dental.2014.12.010

31. Miletic V, Pongprueksa P, De Munck J, Brooks NR, Van Meerbeek B. Curing characteristics of flowable and sculptable bulk-fill composites. Clin Oral Investig. 2017;21(4):1201-1212. doi:10.1007/s00784-0161894-0

32. Andreatta LML, Furuse AY, Prakki A, Bombonatti JFS, Mondelli RFL. Pulp chamber heating: an in vitro study evaluating different light sources and resin composite layers. Braz Dent J. 2016;27(6):675-680. doi:10.1590/0103-6440201600328

33. Braga SS, Oliveira LR, Ribeiro MT, et al. Effect of simulated pulpal microcirculation on temperature when light curing bulk fill composites. Oper Dent. 2019;44(3):289-301. doi:10.2341/17-351-L

34. Kim RJ, Son SA, Hwang JY, Lee IB, Seo DG. Comparison of photopolymerization temperature increases in internal and external positions of composite and tooth cavities in real time: incremental fillings of microhybrid composite vs. bulk filling of bulk fill composite. J Dent. 2015;43(9):1093-1098. doi:10.1016/j.jdent.2015.07.003

35. Kim MJ, Kim RJ, Ferracane J, Lee IB. Thermographic analysis of the effect of composite type, layering method, and curing light on the temperature rise of photo-cured composites in tooth cavities. Dent Mater. 2017;33(10):e37383. doi:10.1016/j.dental.2017.07.007

36. Jo SA, Lee CH, Kim MJ, Ferracane J, Lee IB. Effect of pulse-widthmodulated LED light on the temperature change of composite in tooth cavities. Dent Mater. 2019;35(4):554-563. doi:10.1016/j. dental.2019.01.009

37. Pereira JC, Weissheimer A, de Menezes LM, de Lima EM, Mezomo M. Change in the pulp chamber temperature with different stripping techniques. Prog Orthod. 2014;15(1):55. doi:10.1186/ s40510-014-0055-8

\section{Publish your work in this journal}

Clinical, Cosmetic and Investigational Dentistry is an international, peer-reviewed, open access, online journal focusing on the latest clinical and experimental research in dentistry with specific emphasis on cosmetic interventions. Innovative developments in dental materials, techniques and devices that improve outcomes and patient satisfaction and preference will be highlighted. The manuscript management system is completely online and includes a very quick and fair peer-review system, which is all easy to use. Visit http://www.dovepress.com/testimonials.php to read real quotes from published authors.

Submit your manuscript here: https://www.dovepress.com/clinical-cosmetic-and-investigational-dentistry-journal 